\title{
Biodireito e legislação na reprodução assistida
}

\author{
Biolaw and legislation on assisted reproduction
}

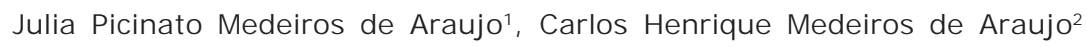

\begin{abstract}
RESUMO
O biodireito é um ramo da ciência jurídica, e por essa lente podemos analisar os princípios e normas que influenciam e modificam as relações com o Estado e entre os próprios indivíduos, quando tratarem sobre a vida e dos direitos fundamentais dos indivíduos envolvidos.

Os principais princípios analisados da bioética são: beneficência, autonomia, justiça, respeito pela pessoa e do consentimento informado.

As pesquisas buscam trazer foco na legislação brasileira a respeito do assunto, a fim de propor uma maior abordagem para facilitar a compreensão das pessoas envolvidas no processo de Reprodução Assistida, tanto pacientes como profissionais. As normas analisadas foram a Constituição Federal, o Código Civil Brasileiro e as Resoluções do Conselho Federal de Medicina (CFM). O texto trata de assuntos polêmicos que envolvem pacientes, equipe multiprofissional e sociedade, pois ao analisar as técnicas de Reprodução Assistida há inúmeras indagações como por exemplo quais os direitos e deveres envolvidos, qual o limite do uso dessas técnicas para ter como resultado a gravidez e quais os direitos fundamentais que estão sendo preservados. Alguns pontos discutidos no trabalho são da cessão temporária do útero, doação de material genético, criopreservação e Reprodução Assistida post-mortem, entre outros. Assim, o desenvolvimento do tema exposto se dá em três momentos, sendo o primeiro o biodireito e os direitos humanos do ponto de vista da Reprodução Assistida, bem como as técnicas utilizadas, em seguida o estudo da legislação brasileira e por fim os aspectos polêmicos e discussões a respeito do tema.
\end{abstract}

Palavras-chave: Medicina Reprodutiva. Bioética. Ética Profissional.

\begin{abstract}
Biolaw is a branch of legal science, through which it's possible to analyze the principles and regulations that influence and modify the relation with the State and among individuals themselves when it comes to the life and fundamental rights of the individuals involved.

The main bioethics principles analyzed are: beneficence, autonomy, justice, respect for the person and the informed consent.

Research aims to focus on the Brazilian legislation on the subject in order to propose a wider approach to promote the comprehension of people involved in the process of Assisted Reproduction,
\end{abstract}

1. Graduação em Direito pela Faculdade de Direito da UNISEB

2. Docente, Licenciatura em Ciências Biológicas da Universidade Federal do Triângulo Mineiro - UFTM
CORRESPONDÊNCIA: Universidade Federal do Triângulo Mineiro - UFTM Instituto de Ciênc. Exatas, Naturais e Educação - ICENE. Departamento de Ciências Biológicas - DCB Campus - Univerdecidade Uberaba - MG Av. Dr. Randolfo Borges Júnior. 38064-200 - Uberaba, MG

Recebido em 08/03/2018 Aprovado em 28/08/2018 
both patients and professionals. The regulations analyzed were the Brazilian Constitution, the Brazilian Civil Code and the Brazilian Federal Medical Council.

The text brings up polemical subjects involving patients, a multiprofessional team and the society, as the Assisted Reproduction techniques are analyzed, numerous questions come up, as what are the rights and obligations involved, what is the limit of using these techniques to achieve pregnancy and what are the fundamental rights which are being preserved. Some of the topics discussed in this research are surrogacy, genetic material donation, cryopreservation and posthumous assisted reproduction.

Therefore, the development of the exposed topic happens in three phases, the first one is Biolaw and Human Rights from the Assisted Reproduction point of view and the techniques that are used, then the study of the Brazilian legislation and finally the polemical aspects and discussions on the topic.

Keywords: Reproductive Medicine. Bioethics. Ethics, Professional.

\section{INTRODUÇÃO}

A Reprodução Assistida (RA) é o conjunto de técnicas que tem o papel de auxiliar na resolução de problemas de reprodução humana, facilitando o processo de procriação. Estas técnicas podem ser utilizadas na preservação social e/ou oncológica de gametas, embriões e tecidos germinativos.

Essas técnicas advêm do grande avanço tecnológico na área da medicina reprodutiva. A tecnologia é o principal aliado na conquista de bons resultados nos tratamentos de RA

Para chegar até o momento atual, a história se inicia com o primeiro bebê gerado por meio de uma técnica de Reprodução in vitro, em 1978, na Inglaterra. Esse fato foi o marco histórico e a partir dele houve inúmeras mudanças para que chegasse a fase atual, tempo em que se pode tentar selecionar o material genético livre de qualquer tipo de doença hereditária, com a finalidade da paciente gerar um bebê geneticamente sem anormalidades.

A rapidez dos avanços nas pesquisas ao longo dos anos, transformou o campo do biodireito e o campo ético, porém, as normas não foram capazes de acompanhar o crescimento das demandas, causando assim, uma grande defasagem na legislação nacional a respeito do tema.

A discussão no campo do biodireito passa por diversas áreas, em que se pode analisar as consequências do uso das técnicas de RA e também os direitos e deveres das pessoas envolvidas no tratamento. Essas técnicas devem seguir uma linha aceitável de respeito à dignidade da pessoa humana e se forem observadas pelas lentes da ética e do biodireito devem se colocar acima de qualquer finalidade lucrativa, mas antes de tudo deve-se prestar ao bem da vida.

A ética é um norte para as ações dos profissionais envolvidos, o qual permite uma avaliação do que é legalmente aceito ou não na sociedade em que se atua. A tecnologia nessa área, como citada anteriormente, pode ocasionar uma distorção sobre o que é ético e causar a sensação de que tudo é impossível e nada é proibido.

A ética profissional, por muitas vezes não ser observada, pode causar danos irreversíveis a saúde da paciente, do bebê a ser gerado e até mesmo cometer atos criminosos ferindo os princípios constitucionais que garantem os direitos dos seres humanos.

É muito importante então, que a ética e o biodireito caminhem atrelados aos avanços possibilitando uma visão humanista e respeitadora dos direitos quanto se trata de RA. Porém, como citado, a legislação brasileira é defasada em relação ao tema, tendo em vista que não há um grande número de normas que preveem os casos de RA e quais suas consequências nos casos concretos.

Há diversos dispositivos legais assentados no ordenamento jurídico brasileiro que tratam das consequências e servem como norte para a utilização da Reprodução in vitro. O Código Civil Brasileiro e a Constituição Federal são fontes legislativas que analisam essas normas com foco no biodireito e trazem regras de conduta para os envolvidos. 
No entanto, não são suficientes para sanar todos os problemas e questionamentos que podem ser gerados, com isso, conjuntamente temos as Resoluções do CFM que trazem regras especificas sobre a temática. Mas, ainda, com a clara defasagem da legislação brasileira, sobre a RA, tramita na Câmara dos Deputados um projeto de lei que pretende regulamentar as condutas e auxiliar os envolvidos no processo de RA.

Esse atraso normativo e a complexidade do tema, juntamente com seus inúmeros pontos polêmicos acabam gerando grande discussão no campo acadêmico e nos grandes centros de pesquisa. Com isso, o trabalho gira em torno dessas discussões e questionamentos, e o objetivo então é tentar compreender as normas existentes e detalhar as polemicas que envolvem o tema.

\section{O CONCEITO DE BIOÉTICA}

A ética tem relação com os aspectos funcionais da sociedade, como a conduta humana e a vida social, existindo em todas as sociedades humanas, sendo um conjunto de princípios e regras. Tem como objetivo estabelecer normas para um convívio em sociedade pacífica ${ }^{1}$.

Analisando conjuntamente a ética e à atuação profissional, podemos verificar que o comportamento desses profissionais e as condutas que adotam é com a finalidade de preservar sempre uma conduta ética-profissional. No caso específico da área médica, a ética pode ser analisada por três aspectos: relação dos médicos com a sociedade, médico paciente e por fim entre os profissionais da área. A relação médico paciente tem primordialmente o objetivo de não ferir a autonomia e igualdade entre os pacientes, sigilo médico e respeito pela vida.

Para normatizar a ética médica e fazer esses valores e princípios, foi lançado o Código de Ética Médica em vigor desde 13 de abril de 2010, com o fundamento de não ferir a Constituição Federal e a legislação brasileira, foi reafirmado os direitos e deveres dos médicos e apresentados os princípios básicos que os profissionais devem seguir.

Alguns princípios são fundamentais e importantíssimos para nortear a conduta médica, as- sim como podemos tirar de exemplos os itens seguintes, que estão no capítulo 1 do Código de Ética Médica:

$[\ldots]$

VI - O médico guardará absoluto respeito pelo ser humano e atuará sempre em seu benefício. Jamais utilizará seus conhecimentos para causar sofrimento físico ou moral, para o extermínio do ser humano ou para permitir e acobertar tentativa contra sua dignidade e integridade.

[...]

XI - O médico guardará sigilo a respeito das informações de que detenha conhecimento no desempenho de suas funções, com exceção dos casos previstos em lei.

Entre as práticas de saúde, surge a bioética que vem para normatizar condutas assistenciais na área da saúde estabelecendo princípios que norteiam o estudo da ética e bioética.

Quando se utiliza a bioética como diretrizes dos estudos, por exemplo na RA, ela serve como orientação para questionamentos sobre responsabilidade e conhecimentos específicos ${ }^{2}$. Para uma análise completa temos que compreender todos os princípios que baseia a ética e a bioética.

\subsection{Princípios éticos gerais}

Os princípios éticos gerais possuem como referência pesquisas em seres humanos, são os principais: respeito pela pessoa, beneficência, justiça, consentimento informado e autonomia ${ }^{2}$.

\section{a. Principio do respeito pela pessoa}

Esse princípio traz como principal fundamento a observância na autonomia da vontade da pessoa humana, trazendo maior proteção a fim de evitar abusos e danos ao maior bem, a vida².

Sendo que pessoas incapazes também estão protegidas por esse princípio, devendo apenas serem representadas e acima de tudo terem sua autonomia preservada.

O paciente deve ter autonomia, desde que em plena consciência, escolher o que quer para si e tomar decisões por si mesmo, não sendo nunca influenciado pelo profissional. Sendo que o profissional da área da saúde apenas deve orientar e nunca causar impacto na decisão do pa- 
ciente. O princípio da autonomia garante que o paciente tenha o livre convencimento com base em suas crenças, preceitos e valores.

\section{b. Princípio da Beneficência}

Baseia-se na necessidade e obrigação do profissional da saúde promover sempre ao seu paciente o bem-estar e ter como função primordial fazer o bem para quem confia em seu trabalho ${ }^{2,3}$.

Sendo que o profissional da saúde deve sempre avaliar o procedimento mais adequado para obter o resultado pretendido e com isso evitar que o paciente não sofra mais que o necessário.

É razoável que o profissional da saúde utilize todos os meios cabíveis a sua disposição para reduzir os riscos e os danos que podem ser causados a saúde do paciente.

\section{c. Principio da Justiça}

O princípio da justiça, como o próprio nome indica é o direito ao acesso justo e igualitário aos serviços de saúde e exercício da medicina. Com isso o profissional de saúde não pode fazer diferenciação entre um paciente e outro e nem privar o cidadão de tratamentos disponíveis em razão de sua cor, idade, religião ou aspectos culturais ${ }^{2}$.

\section{d. Princípio do Consentimento informado}

Em relação a esse princípio há uma divergência de entendimento entre os doutrinadores. Alguns compreendem que esse princípio é indispensável e que o mesmo deve ser colocado no rol dos princípios gerais da bioética.

A base fundamental desse princípio é de sempre manter o paciente informado acerca das técnicas a serem utilizadas e ter de maneira inequívoca o consentimento livre por parte deste, sempre que possível de forma escrita.

\section{e. Princípio da autonomia}

Esse princípio tem como fundamento a liberdade do paciente de rejeitar ou aceitar o tratamento que o médico propõe. Por esse princípio o paciente pode agir de forma voluntaria, livre e esclarecida.

A aplicação desse princípio também pode ser ao médico, nos casos em que podem rejeitar solicitações que são confrontantes a seu conhecimento e sua consciência.

\section{O CONCEITO DE BIODIREITO}

O direito é uma ciência que tem por objetivo normatizar as condutas humanas. Torna-se um conjunto de normas jurídicas impostas pelo Estado afim de garantir um convívio pacifico entre os indivíduos em sociedade.

Com o aumento das pesquisas e da ânsia por mais tecnologias, a comunidade cientifica sentiu a necessidade de criar normas para limitar os conceitos éticos que poderiam ser aplicados nas pesquisas e nos tratamentos em seres humanos.

O biodireito entra como normatização dessas condutas pois determina um conjunto de normas voltadas as condutas desses profissionais, impondo regras a serem observadas.

A maior fonte do biodireito é a Constituição Federal $^{4}$ de 1988, que tem como inspiração as discussões da bioética e seus princípios. Com essa normatização temos como fundamento primordial o respeito pela dignidade da pessoa, direito a vida, proibição a qualquer tipo de comercialização de partes do corpo para fins de transplantes, preservação da integridade física e por fim do patrimônio genético.

Para muitos doutrinadores o biodireito não é considerado como ciência jurídica, sendo analisado como direito de 4 o geração que analisa o progresso técnico-cientifico do homem, fundamentando no direito constitucional, civil e penal

Ao se fundamentar no direito constitucional a finalidade é garantir o respeito aos direitos fundamentais, como direito a vida, dignidade, liberdade e saúde. No âmbito do direito civil há integração com o biodireito no que diz respeito ao direito da personalidade, cabendo a análise de quando se inicia a vida e por consequência quando se tem início os direitos do nascituro. E mais, ainda no código civil que encontra os direitos referentes a disposição do próprio corpo ou parte dele, durante a vida ou após ela.

E por fim, o direito penal, que auxilia o biodireito no que tange a regulamentação das condutas criminais a respeito do tema, por exemplo na proibição do aborto, instituindo uma pena para tal procedimento. O biodireito além de basear-se no direito penal, constitucional e civil, se fundamenta em alguns princípios constitucionais:

a) Dignidade da pessoa humana (artigo 1ㅇ, III, $\mathrm{CF} / 88$ ); 
b) Princípio da igualdade (artigo 5ㅇ, caput, $\mathrm{CF} / 88$ ): "todos são iguais perante a lei, sem distinção de qualquer natureza, garantindo-se aos brasileiros e aos estrangeiros residentes no país a inviolabilidade do direito à vida, à liberdade, à igualdade, à segurança, à propriedade...";

c) Proibição de tortura e tratamento desumano (artigo5이 III, CF/88): "ninguém será submetido a tortura nem a tratamento desumano ou degradante";

d) Acesso à justiça (artigo 5o, XXXV, CF/88): "a lei não excluirá da apreciação do Poder Judiciário lesão ou ameaça a direito";

e) Proteção aos direitos fundamentais (artigo 5, $X \mathrm{LI}, \mathrm{CF} / 88$ ): "a lei punirá qualquer discriminação atentatória dos direitos e liberdades fundamentais";

f) Direito a saúde (artigo196, CF/88) - "a saúde é um direito de todos e dever do Estado, garantido mediante políticas sociais e econômicas que visem à redução do risco de doença e de outros agravos e ao acesso universal e igualitário às ações e serviços para sua promoção, proteção e recuperação".

Assim, nota-se que o biodireito traz grandes questionamentos a respeito de uso de célula tronco, técnicas de RA, uso de embriões excedentes, dentre outros.

\subsection{Biodireito e os direitos humanos}

Os direitos humanos também têm como foco as relações e as condutas humanas como o biodireito, neste tem principalmente os direitos dos seres humanos com a premissa de não haver distinção de gênero, etnia, religião, nacionalidade ou qualquer outra condição ${ }^{5}$.

O objetivo é de resguardar o direito à vida, à liberdade, à liberdade de expressão, à educação entre outros. Não podendo excluir esses direitos de ninguém, sendo assim, não sendo permitido a discriminação.

Assim como os princípios constitucionais do biodireito citados anteriormente, podemos também considerá-los como norte para os direitos humanos, por ter também base constitucional e andarem lado a lado. Porém, os direitos humanos são garantidos por varias leis tanto no âmbito nacional como por normas e documentos internacionais ${ }^{5}$.
Como exemplo de importante organização dos direitos humanos temos a Declaração Universal dos Direitos Humanos, de 1948, que foi criada para delinear os diretos humanos básicos, essa declaração foi um marco na história dos direitos inerentes aos seres humanos ${ }^{5}$.

A declaração Universal dos Direitos Humanos foi proclamada pela assembleia da ONU ${ }^{6}$ (Organização das Nações Unidas), e um dos principais objetivos era que os direitos ali tratados fossem observados por todas as nações. De acordo com Bobbio (2004, p. 27): “[ ...] foi acolhido como inspiração e orientação no processo de crescimento de toda a comunidade internacional no sentido de uma comunidade não só de Estados, mas de indivíduos livres e iguais".

Seguindo essa ideia foi escrita a Declaração Universal sobre Bioética e Direitos Humanos da UNESCO ${ }^{7}$ (Organização das Nações Unidas para a Educação, Ciência e Cultura), de 2006.

No prefácio dessa declaração, explica-se os objetivos que trouxeram a criar e a fundamentar essa recente declaração específica, como se nota:

Ao tratar das questões éticas suscitadas pela medicina, ciências da vida e tecnologias associadas na sua aplicação aos seres humanos, a Declaração, tal como o título indica, incorpora os princípios que enuncia nas regras que norteiam o respeito pela dignidade humana, pelos direitos humanos e pelas liberdades fundamentais. Ao consagrar a bioética entre os direitos humanos internacionais e ao garantir a interligação que existe entre ética e direitos humanos no domínio específico da bioética.

Independentemente das declarações e normas para garantir os direitos humanos a todos, eles devem ser respeitados, como apresentado por Norberto Bobbio ${ }^{4}$ (2004, p. 25):

Não se trata de saber quais e quantos são esses direitos, qual é sua natureza e seu fundamento, se são direitos naturais ou históricos, absolutos ou relativos, mas sim qual é o modo mais seguro para garanti-los, para impedir que, apesar de solenes declarações, eles sejam continuamente violados.

Ao estudar essa Declaração observa-se que o objetivo efetivo é orientar os avanços ci- 
entíficos e a transformação social sendo considerado um guia para as nações para elaboração de legislação. Pode-se claramente notar que os princípios abordados especificamente pela Declaração Universal sobre Bioética e Direitos Humanos foram citados como princípios constitucionais anteriormente ao analisar o biodireito isoladamente. Essa Declaração, então pode ser considerada como uma fonte para as normas de biodireito e consequentemente para práticas que envolvem a vida humana, como no caso da RA.

\section{REPRODUÇÃO ASSISTIDA}

A Reprodução Assistida (RA) é o conjunto de técnicas que tem o papel de auxiliar na resolução de problemas de reprodução humana, facilitando o processo de procriação. Estas técnicas podem ser utilizadas na preservação social e/ou oncológica de gametas, embriões e tecidos germinativos.

Foi no ano de 1978 o nascimento do primeiro "bebê de proveta" no mundo, na Inglater$\mathrm{ra}$, vinda de pesquisas sem precedentes na cidade de Cambridge. Já no Brasil a técnica de RA chega anos depois, gerando a primeira criança no ano de 1984.

Hoje no Brasil, sem dúvida, temos clinicas e técnicas tão sofisticadas e modernas quanto dos países denominados mais desenvolvidos.

A interação nessa área entre os pesquisadores brasileiros e estrangeiros, o intercâmbio de informações e a busca por novas tecnologias é continuo.

Atualmente milhares de crianças nascem por meio de técnicas de RA em todo mundo, o que nos permite concluir que cada vez mais as pessoas, sobretudo mulheres, submetem-se as referidas técnicas, na esperança de alcançar a almejada maternidade.

- O índice de gravidez positiva em grandes laboratórios e clinicas de RA é em média de $50 \%$, porém considerando a idade materna essa porcentagem cai drasticamente de acordo com dados publicados pela Rede Latino-americana ${ }^{8}$ de Reprodução Assistida, de 2014.

Nota-se assim, que mesmo com a utilização de técnicas modernas de RA, o grande avan- ço tecnológico e os contínuos estudos nessa área, a taxa de gravidez é relativamente baixa, tendo em vista os vários fatores que influenciam para que se tenha um resultado positivo.

A RA consiste numa série de procedimentos biotecnológicos com a participação de equipe multiprofissional, que tem como objetivo principal a contemplação da gravidez para casais, que em condições naturais, não conseguem atingir a plenitude da maternidade e paternidade.

De modo geral esta intervenção biotecnológica provocará mudança significativa na vida de quem optou pela mesma, pois a partir do sucesso das técnicas empregadas, uma nova vida será gerada.

Conforme a autora Maria Helena Diniz ${ }^{9}$ (2014, p. 44):

As práticas das "ciências da vida" que podem trazer enormes benefícios à humanidade, contem riscos potenciais muito perigosos e imprevisíveis, e por tal razão, os profissionais da saúde devem estar sempre atentos para que não transponham os limites éticos impostos pelo respeito à pessoa humana e à sua vida, integridade e dignidade.

Todos profissionais da área de saúde como médicos, enfermeiros, biólogos, psicólogos, embriologistas, entre outros, envolvidos nas técnicas de RA devem sempre respeitar, acima de qualquer coisa, a dignidade da pessoa humana para haver a efetividade dos direitos humanos.

O respeito à vida e sua preservação são valores inerentes à própria natureza humana e como tal estes valores devem acompanhar a prática profissional dentro da ética estabelecida pelos conselhos de classes de cada um dos especialistas envolvidos nos procedimentos de RA.

$\mathrm{Na}$ Constituição Federal, de 1988, no artigo 5o encontramos a essência de preservação da vida humana, para garantir a inviolabilidade do direito à vida. Diante desse artigo temos como premissa que a vida é um bem tutelado pelo direito, protegida contra tudo e contra todos. Inclusive, temos que a vida humana é protegida até mesmo de seu titular por ser irrenunciável e inviolável. Além das normas constitucionais, a vida recebe proteção pelas normas cíveis e penais. 


\section{TÉCNICAS DE RA}

São técnicas que interferem no ato reprodutivo, com a utilização de medicamentos, equipamentos de laboratório, manipulação de materiais biológicos como gametas e embriões, com o objetivo de conseguir realizar a fecundação fora do corpo da mulher. Os casais que buscam o auxílio para conseguir a gravidez em centros de RA geralmente são diagnosticados com esterilidade ou problemas de infertilidade.

A diferença entre os dois conceitos, é basicamente que, um casal estéril, tem a capacidade de gerar um filho de modo natural nula, por exemplo, quando a mulher não possui as duas tubas uterinas. Nos casos de casais inférteis, ocorre diminuição na chance de gravidez, como por exemplo, a mulher com endometriose ou algum tipo de disfunção hormonal.

Os casais inférteis e estéreis já têm à disposição várias formas de driblar os problemas de infertilidade e esterilidade masculina e feminina, e cada vez mais rápido surgem, novas técnicas que auxiliam nessas dificuldades.

Atualmente, existem vários métodos utilizados como técnicas de RA. Entre elas podemos destacar: a Inseminação Intra Útero (IUI), Fertilização in vitro (FIV), Injeção Intracitoplasmática de Espermatozoide (ICSI).

Um ponto importante a ser considerado é que os procedimentos podem ser do tipo heteróloga ou homóloga. Segundo Silvio Rodrigues et al. (apud SCALQUETTE et al, 2010) "homóloga é a inseminação promovida com material genético (espermatozoide e oócito II) dos próprios cônjuges, e heteróloga é a fecundação realizada com material genético de pelo menos um terceiro, aproveitando ou não gametas de um ou de outro cônjuge. “

Ao analisar essas técnicas podemos verificar como é acelerado os avanços tecnológicos no campo da RA, porém, esses avanços causam cada vez mais implicações éticas, jurídicas e sociais.

As atuações dos profissionais na área devem ser normatizadas, porém atualmente a legislação brasileira tem falhas neste ponto, causando assim muitas discussões acerca da atualização das referidas técnicas e questionamentos de como se devem proceder em casos polêmicos, como por exemplo de criopreservação dos embriões ou RA post-mortem. Ainda assim, independentemente das técnicas utilizadas, o casal deve ter sempre os seus direitos respeitados, ser informado sobre todas as possibilidades e riscos que podem trazer a escolha pela RA.

\section{LEGISLAÇÃO PARA UTILIZAÇÃO DAS TÉCNICAS DE RA}

\subsection{Código Civil Brasileiro}

Há uma grande importância em analisar juntamente com o tema, as legislações existentes no Brasil que tratam do assunto. Porém não é uma simples tarefa achar normas específicas para RA tendo em vista que é um tema com modificações constantes e avanços incessantes.

No Brasil a legislação atual se compreende entre a Constituição Federal, o Código Civil Brasileiro, a Resolução do CFM. E ainda, há um projeto de lei que tramita na Câmara dos Deputados com a finalidade de instituir o Estatuto da RA.

O nosso ordenamento jurídico é bem distante da realidade quando se trata da RA. O Código Civil de 2002 apenas trata de assuntos relacionados a paternidade na ocasião de filhos concebidos pelas técnicas de RA, não trazendo em nenhum artigo de modo a regularizar as técnicas utilizadas.

A previsão legal do Código Civil de 2002, no artigo 1. 597, em seus incisos III, IV e V traz três hipóteses de presunção de filiação:

Art. 1.597. Presumem-se concebidos na constância do casamento os filhos:

I - nascidos cento e oitenta dias, pelo menos, depois de estabelecida a convivência conjugal;

II - nascidos nos trezentos dias subsequentes à dissolução da sociedade conjugal, por morte, separação judicial, nulidade e anulação do casamento;

III - havidos por fecundação artificial homóloga, mesmo que falecido o marido; IV - havidos, a qualquer tempo, quando se tratar de embriões excedentários, decorrentes de concepção artificial homóloga;

V - havidos por inseminação artificial heteróloga, desde que tenha prévia autorização do marido. 
Notamos que o legislador teve a perspectiva da RA por dois pontos, a In Vivo, fertilização que ocorre dentro do próprio corpo da mulher e a In Vitro, que ocorre em laboratório, a união dos gametas femininos e masculinos.

E mais, no ordenamento jurídico foi feita a distinção das formas homologas e heterólogas de fecundação, e suas diferenças na relação à presunção de paternidade em cada uma delas.

\subsection{Consequências jurídicas da fecunda- ção homóloga}

Na fecundação homóloga, como já citado, se usa o material genético do próprio casal. Assim pode-se presumir com base no Código Civil que o marido é o próprio pai da criança concebida. No caso desse marido querer afastar essa presunção que o ordenamento impõe é preciso a comprovação que houve um erro médico e que o sêmen utilizado não foi o do marido e sim de um terceiro desconhecido.

A insegurança jurídica, neste caso, poderia ocorrer quando o homem falece e deixa embriões oriundos do seu próprio material genético congelado. Assim até que ponto sua cônjuge poderia usar esse embrião para engravidar depois do óbito do marido?

O prazo para que essa gravidez ocorra não é estipulado em lei, porém o legislador presume essa paternidade apenas se os embriões excedentes foram fecundados homologamente (material genético do próprio casal).

E toda problemática ocorreria com a transmissão dos bens que obrigatoriamente ocorre com a morte do de cujus. Muitos concordam que essa seria a hora de avaliar quem seria os herdeiros de todos os bens deixados pela pessoa falecida.

Porém há previsão legal que permite ao de cujus deixar a herança, por meio de testamento, para quem desejar, inclusive para o filho ainda não concebido. Essa permissividade gera dúvidas de como essa problemática pode ser tratada, visto que seria necessário guardar a parte do quinhão desse futuro filho, mesmo que não se tenha certeza de que será gerado, causando grande confusão e insegurança jurídica.

A intensão do legislador, ao permitir que se conceba o filho mesmo após a morte do de cujus, não é estimular a pratica da RA post-mortem mas preservar as escolhas do casal.

\subsection{Consequências jurídicas da fecunda- ção heteróloga}

As consequências da fecundação heteróloga são consideradas mais gravosas pelo fato de ter a intervenção do material genético de um terceiro.

Para casais heterossexuais, a RA heteróloga com utilização de espermatozoides de um terceiro é indicada quando se tem impossibilidade de obtenção de espermatozoides e/ou com a finalidade de se evitar transmissão de algumas doenças genéticas.

A doação de sêmen, segundo o direito brasileiro deve ser anônima, sem fins lucrativos e o homem ter entre 18 e 50 anos. É necessário, também, que o material seja livre de qualquer tipo de doença transmissível sexualmente, como exemplo a AIDS e não pode ter nenhuma alteração como alteração na quantidade de espermatozoides. Por fim, a doação deve ser espontânea e sem fins lucrativos.

Pode também ocorrer a fecundação heteróloga com a doação de embrião, nesses casos se tem infertilidade por parte do homem e da mulher, esses embriões doados são os excedentes de um procedimento de outro casal. Podendo por fim, também ocorrer a doação de oócitos.

Essas técnicas de doação estão previstas no artigo 199, §4으 da Constituição Federal de 1988:

Art. 199 - A assistência à saúde é livre à iniciativa privada.

$\S 1$ 을 As instituições privadas poderão participar de forma complementar do sistema único de saúde, segundo diretrizes deste, mediante contrato de direito público ou convênio, tendo preferência as entidades filantrópicas e as sem fins lucrativos.

§ 2o É vedada a destinação de recursos públicos para auxílios ou subvenções às instituições privadas com fins lucrativos. § 3o - É vedada a participação direta ou indireta de empresas ou capitais estrangeiros na assistência à saúde no País, salvo nos casos previstos em lei.

§ 4ํ A lei disporá sobre as condições e os requisitos que facilitem a remoção de 
órgãos, tecidos e substâncias humanas para fins de transplante, pesquisa e tratamento, bem como a coleta, processamento e transfusão de sangue e seus derivados, sendo vedado todo tipo de comercialização.

De acordo com o inciso $\mathrm{V}$ do artigo 1.597 do Código Civil é necessária prévia autorização do marido para se fazer a fecundação heteróloga por meio de técnicas de RA para que seja considerado o nascituro filho do casal. Por outro lado, no tocante ao que se trata, de técnica de RA, feita a partir do recebimento de material genético feminino de uma doadora, a legislação não tem previsão para o caso, como citado por Scalquette ${ }^{2}$.

\subsection{Resolução do CFM}

A resolução mais recente do CFM foi publicada no D.O.U em 21 de setembro de 2017. Esta resolução traz novos parâmetros para os profissionais da área de saúde e para os que atuam no campo da RA, tentando ao máximo amenizar as lacunas existentes na legislação brasileira.

A resolução do CFM é fundamentalmente uma orientação para os profissionais, que atuam na área médica, e se deparam com duvidas durante a rotina de trabalho no dia-a-dia. Todas as resoluções que tratam de RA buscam conciliar suas técnicas com os princípios da ética médica.

Mesmo não tendo força normativa geral e abstrata, a resolução do CFM serve como paradigma ético-biológico para utilização das técnicas de RA.

Como pontos importantes para se conduzir o procedimento de RA da melhor forma, possível, temos os princípios gerais, publicados na Resolução do CFM:

\section{I- PRINCÍPIOS GERAIS}

1. As técnicas de reprodução assistida (RA) têm o papel de auxiliar na resolução dos problemas de reprodução humana, facilitando o processo de procriação. 2. As técnicas de RA podem ser utilizadas na preservação social e/ou oncológica de gametas, embriões e tecidos germinativos. 3. As técnicas de RA podem ser utilizadas desde que exista probabilidade de sucesso e não se incorra em risco grave de saúde para o (a) paciente ou o possível descendente. §1으 A ida- de máxima das candidatas à gestação por técnicas de RA é de 50 anos. § 2 o As exceções a esse limite serão aceitas baseadas em critérios técnicos e científicos fundamentados pelo médico responsável quanto à ausência de comorbidades da mulher e após esclarecimento ao (s) candidato (s) quanto aos riscos envolvidos para a paciente e para os descendentes eventualmente gerados a partir da intervenção, respeitando-se a autonomia da paciente. 4. O consentimento livre e esclarecido será obrigatório para todos os pacientes submetidos às técnicas de RA. Os aspectos médicos envolvendo a totalidade das circunstâncias da aplicação de uma técnica de RA serão detalhadamente expostos, bem como os resultados obtidos naquela unidade de tratamento com a técnica proposta. As informações devem também atingir dados de caráter biológico, jurídico e ético. O documento de consentimento livre e esclarecido será elaborado em formulário especial e estará completo com a concordância, por escrito, obtida a partir de discussão bilateral entre as pessoas envolvidas nas técnicas de reprodução assistida. 5. As técnicas de RA não podem ser aplicadas com a intenção de selecionar o sexo (presença ou ausência de cromossomo Y) ou qualquer outra característica biológica do futuro filho, exceto para evitar doenças no possível descendente. 6. É proibida a fecundação de oócitos humanos com qualquer outra finalidade que não a procriação humana. 7. Quanto ao número de embriões a serem transferidos, fazem-se as seguintes determinações de acordo com a idade: a) mulheres até 35 anos: até 2 embriões; b) mulheres entre 36 e 39 anos: até 3 embriões; c) mulheres com 40 anos ou mais: até 4 embriões; d) nas situações de doação de oócitos e embriões, considera-se a idade da doadora no momento da coleta dos oócitos. O número de embriões a serem transferidos não pode ser superior a quatro. 8. Em caso de gravidez múltipla decorrente do uso de técnicas de RA, é proibida a utilização de procedimentos que visem a redução embrionária.

\section{II- PACIENTES DAS TÉCNICAS DE RA}

1. Todas as pessoas capazes, que tenham solicitado o procedimento e cuja indicação não se afaste dos limites desta resolução, podem ser 
receptoras das técnicas de RA, desde que os participantes estejam de inteiro acordo e devidamente esclarecidos, conforme legislação vigente. 2. É permitido o uso das técnicas de RA para relacionamentos homoafetivos e pessoas solteiras, respeitado o direito a objeção de consciência por parte do médico. 3. É permitida a gestação compartilhada em união homoafetiva feminina em que não exista infertilidade. Considera-se gestação compartilhada a situação em que o embrião obtido a partir da fecundação do (s) oócito (s) de uma mulher é transferido para o útero de sua parceira.

\section{III- REFERENTE ÀS CLÍNICAS, CENTROS OU SERVIÇOS QUE APLICAM TÉCNICAS DE RA}

As clínicas, centros ou serviços que aplicam técnicas de RA são responsáveis pelo controle de doenças infectocontagiosas, pela coleta, pelo manuseio, pela conservação, pela distribuição, pela transferência e pelo descarte de material biológico humano dos pacientes das técnicas de RA. Devem apresentar como requisitos mínimos: 1. Um diretor técnico (obrigatoriamente um médico registrado no Conselho Regional de Medicina de sua jurisdição) com registro de especialista em áreas de interface com a RA, que será responsável por todos os procedimentos médicos e laboratoriais executados; 2 Um registro permanente (obtido por meio de informações observadas ou relatadas por fonte competente) das gestações, dos nascimentos e das malformações de fetos ou recém-nascidos provenientes das diferentes técnicas de RA aplicadas na unidade em apreço, bem como dos procedimentos laboratoriais na manipulação de gametas e embriões; 3. Um registro permanente dos exames laboratoriais a que são submetidos os pacientes, com a finalidade precípua de evitar a transmissão de doenças; 4.Os registros deverão estar disponíveis para fiscalização dos Conselhos Regionais de Medicina.

\section{IV- DOAÇÃO DE GAMETAS OU EMBRIÕES}

1. A doação não poderá ter caráter lucrativo ou comercial. 2. Os doadores não devem conhecer a identidade dos receptores e vice-versa. 3. A idade limite para a doação de gametas é de 35 anos para a mulher e de 50 anos para o homem. 4 Será mantido, obrigatoriamente, sigilo sobre a identidade dos doadores de gametas e embriões, bem como dos receptores. Em situações especiais, informações sobre os doadores, por motivação médica, podem ser fornecidas exclusivamente para médicos, resguardando-se a identidade civil do (a) doador (a). 5. As clínicas, centros ou serviços onde são feitas as doações devem manter, de forma permanente, um registro com dados clínicos de caráter geral, características fenotípicas e uma amostra de material celular dos doadores, de acordo com legislação vigente. 6. Na região de localização da unidade, o registro dos nascimentos evitará que um (a) doador (a) tenha produzido mais de duas gestações de crianças de sexos diferentes em uma área de um milhão de habitantes. Um (a) mesmo (a) doador (a) poderá contribuir com quantas gestações forem desejadas, desde que em uma mesma família receptora. 7. A escolha das doadoras de oócitos é de responsabilidade do médico assistente. Dentro do possível, deverá garantir que a doadora tenha a maior semelhança fenotípica com a receptora. 8. Não será permitido aos médicos, funcionários e demais integrantes da equipe multidisciplinar das clínicas, unidades ou serviços participar como doadores nos programas de RA. 9. É permitida a doação voluntária de gametas, bem como a situação identificada como doação compartilhada de oócitos em RA, em que doadora e receptora, participando como portadoras de problemas de reprodução, compartilham tanto do material biológico quanto dos custos financeiros que envolvem o procedimento de RA. A doadora tem preferência sobre o material biológico que será produzido.

\section{V- CRIOPRESERVAÇÃO DE GAMETAS OU EM- BRIÕES}

1. As clínicas, centros ou serviços podem criopreservar espermatozoides, oócitos embriões e tecidos gonádicos. 2. O número total de embriões gerados em laboratório será comunicado aos pacientes para que decidam quantos embriões serão transferidos a fresco conforme determina esta Resolução. Os excedentes, viáveis, devem ser criopreservados. 3. No momento da criopreservação, os pacientes devem mani- 
festar sua vontade, por escrito, quanto ao destino a ser dado aos embriões criopreservados em caso de divórcio ou dissolução de união estável, doenças graves ou falecimento de um deles ou de ambos, e quando desejam doá-los. 4. Os embriões criopreservados com três anos ou mais poderão ser descartados se esta for a vontade expressa dos pacientes. 5. Os embriões criopreservados e abandonados por três anos ou mais podem ser descartados. Parágrafo único: Embrião abandonado é aquele em que os responsáveis descumpriram o contrato pré-estabelecido e não foram localizados pela clínica.

\section{VI- DIAGNÓSTICO GENÉTICO PRÉ IMPLANTACIONAL DE EMBRIÕES}

1. As técnicas de RA podem ser aplicadas à seleção de embriões submetidos a diagnóstico de alterações genéticas causadoras de doenças podendo nesses casos ser doados para pesquisa ou descartados, conforme a decisão do (s) paciente(s) devidamente documentada em consentimento informado livre e esclarecido específico. 2. As técnicas de RA também podem ser utilizadas para tipagem do sistema HLA do embrião, no intuito de selecionar embriões HLA compatíveis com algum irmão já afetado pela doença e cujo tratamento efetivo seja o transplante de células tronco, de acordo com a legislação vigente. 3. O tempo máximo de desenvolvimento de embriões in vitro será de até 14 dias.

\section{VII- SOBRE A GESTAÇÃO DE SUBSTITUIÇÃO (CESSÃO TEMPORÁRIA DO ÚTERO)}

As clínicas, centros ou serviços de reprodução assistida podem usar técnicas de RA para criarem a situação identificada como gestação de substituição, desde que exista um problema médico que impeça ou contraindique a gestação na doadora genética, em união homoafetiva ou pessoa solteira. 1. A cedente temporária do útero deve pertencer à família de um dos parceiros em parentesco consanguíneo até o quarto grau (primeiro grau-mãe/filha; segundo grauavó/irmã; terceiro grau- tia/sobrinha; quarto grau-prima). Demais casos estão sujeitos à autorização do Conselho Regional de Medicina.
2. A cessão temporária do útero não poderá ter caráter lucrativo ou comercial. 3. Nas clínicas de reprodução assistida, os seguintes documentos e observações deverão constar no prontuário da paciente: 3.1.Termo de consentimento livre e esclarecido assinado pelos pacientes e pela cedente temporária do útero, contemplando aspectos biopsicossociais e riscos envolvidos no ciclo gravídico-puerperal, bem como aspectos legais da filiação; 3.2. Relatório médico com o perfil psicológico, atestando adequação clínica e emocional de todos os envolvidos; 3.3 Termo de Compromisso entre o (s) paciente (s) e a cedente temporária do útero (que receberá o embrião em seu útero), estabelecendo claramente a questão da filiação da criança; 3.4. Compromisso, por parte do (s) paciente (s) contratante (s) de serviços de RA, de tratamento e acompanhamento médico, inclusive por equipes multidisciplinares, se necessário, à mãe que cederá temporariamente o útero, até o puerpério; 3.5 . Compromisso do registro civil da criança pelos pacientes (pai, mãe ou pais genéticos), devendo esta documentação ser providenciada durante a gravidez; 3.6. Aprovação do cônjuge ou companheiro, apresentada por escrito, se a cedente temporária do útero for casada ou viver em união estável.

\section{VIII- REPRODUÇÃO ASSISTIDA POST-MORTEM}

É permitida a reprodução assistida post-mortem desde que haja autorização prévia específica do (a) falecido(a) para o uso do material biológico criopreservado, de acordo com a legislação vigente.

\section{IX- DISPOSIÇÃO FINAL}

Casos de exceção, não previstos nesta resolução, dependerão da autorização do Conselho Regional de Medicina da jurisdição e, em grau recursal, ao Conselho Federal de Medicina.

Nota a permissão, a partir da resolução, da gestação compartilhada em união homoafetiva feminina em que não existe infertilidade. Assim, na prática poderá a mulher receber o embrião, gerado a partir da fertilização de um oócito, de sua parceira. 


\subsection{Projeto de lei com regras para RA}

Os profissionais da área médica hoje têm como norte para utilização das técnicas de RA apenas a resolução proposta pelo CFM, pois não há leis especificas para o caso.

Porém há um projeto de lei que tramita na Câmara dos Deputados ${ }^{11}$, que é o PL 115/15 que "institui o Estatuto da RA, para regular a aplicação e utilização das técnicas de RA e seus efeitos no âmbito das relações civis sociais".

No referido projeto de lei coloca-se como necessário a observância de diversos princípios para a aplicação e utilização das técnicas médicas de RA. Os princípios são: respeito a vida humana, serenidade familiar, igualdade, dignidade da pessoa humana, superior interesse do menor, paternidade responsável, liberdade de planejamento familiar, proteção integral da família, autonomia da vontade, boa-fé objetiva, transparência e subsidiariedade.

No artigo 19 do projeto de lei, permite-se a identificação biológica do doador em garantia da pessoa concebida por fertilização heteróloga, priorizando o conhecimento da origem biológica, porém essa quebra de sigilo apenas poderá ser feita com autorização judicial com interesse relevante para garantir o maior bem jurídico, que é a vida.

Esse projeto tem também a intenção de regulamentar o número de embriões a serem transferidos para a receptora, regra que não tratada em nenhuma outra norma jurídica, apenas convencionada pela ética e os conselhos médicos. Assim, ficaria que é apenas possível a transferência de até dois embriões nos casos de mulher com até 35 anos de idade; até três embriões se a receptora tem entre 36 a 39 anos e para muIheres com 40 anos ou mais pode-se transferir até quatro embriões.

Outro ponto importante que o PL115/2015 trata é dos embriões criopreservados, e deixa expressamente obrigatório ao casal que for beneficiado pela técnica expressar de forma escrita o qual destino deve ser dado aos embriões congelados, nos casos de rompimento da sociedade conjugal, união estável, doença grave ou faleci- mento de um deles ou ambos ou até mesmo no caso de desistência do tratamento.

No mais, se o projeto de lei for aprovado teremos claramente quais poderão ser as destinações a esses embriões criopreservados. E assim poderá ser feita a implantação pelo casal, os próprios "donos" do embrião, podem ser entregues para adoção ou enviados para pesquisa. Não havendo assim dúvidas sobre a destino que se deve dar a esses embriões e nem correr o risco de serem "descartados" for falta de regulamentação pelo ordenamento jurídico, como é o caso atualmente.

\section{ASPECTOS POLÊMICOS DA RA}

\subsection{Status moral do embrião}

O status moral do embrião está ligado a questões e debates éticos sobre quando se inicia a vida, e uma das controversas de todo o tema é se pode considerar o embrião como ser humano ${ }^{2}$.

Se for levar em conta que a vida se inicia em estado de embrião, logo após a fecundação, terá já nessa fase todos os direitos de um ser humano já formado, e deve ser protegido como se assim fosse ${ }^{3}$.

Para esse raciocínio temos dois argumentos muito plausíveis. O primeiro é de que como o embrião se tornará uma pessoa no futuro, já teria como considerar que a vida se inicia ali ou pelo argumento de como está formando o embrião, este necessariamente tem direito à vida.

Diferentemente desses argumentos apresentados estão os que consideram o embrião apenas como um conjunto de células e assim não havendo base para ser tratado diferente disso, isto é, não possui direitos. Por fim, ainda temos os que de forma intermediaria, aceitam a ideia de que o embrião possui um status especial, mas que não há justificativa para protege-lo diferentemente da forma em que se apresenta ${ }^{2,3}$.

Com o surgimento de técnicas reprodutivas e consequentemente o manuseio de embriões pode-se notar um aumento dos questionamentos sobre e como se dá as condutas relacionadas aos embriões excedentes das técnicas de RA e congelamento embrionário. 


\subsection{Embriões excedentes}

A técnica de Fertilização in vitro obtém, na maioria das vezes, um número muito maior de embriões do que realmente serão transferidos para o útero materno, pois a técnica também consiste na seleção de embriões que tiveram melhor desenvolvimento, isto é, de boa qualidade e que tem a maior chance de posteriormente gerar uma gravidez.

Os embriões excedentes, por serem considerados ineptos para implantação, geram grande discussão sobre qual a destinação correta que se deve dar aos mesmos. Pesquisadores da área de Ciências Biológicas questionam se esses embriões simplesmente não poderiam ser utilizados como fonte de material genético e dar a eles a livre utilização em pesquisas.

Porém, por outro lado, considera se que a sua utilização demanda cuidados nos aspectos éticos e assim deve-se realizar o seu congelamento até que a legislação a respeito do tema seja definida pelos legisladores. Esse ponto de vista é muito mais aceitável se analisada a discussão pelo ponto de vista ético. Ainda existe a opção de utilização dos embriões excedentes para terapia de doenças genéticas e hereditárias graves.

Diante de tudo isso se tem um grave aspecto muito questionável que é quando a mãe (aquela que concedeu o material genético) não quer ficar na posse dos embriões excedentes, nestes casos será que estes podem ser doados, ou utilizados para outros fins ou até mesmo descartados?

Questões como essas são de difícil solução, porém uma maneira de mudar esse cenário seria evitar a produção de embriões excedentes, criando limitação para a produção dos mesmos, fazendo-se assim número menor de embriões e com isso concedendo possibilidade de transferência de todos os embriões formados ao útero da muIher sem lhe trazer nenhum tipo de prejuízo.

\subsection{Congelamento de embrião}

Um grande número de casais, ao se submeterem as técnicas de RA optam pelo congelamento ou criopreservação de embriões, com o objetivo de aumentar a chance de gravidez acumulativa por ciclo de tratamento.
O congelamento de embriões é um procedimento adotado quando não é recomendado a transferência a fresco ou quando há embriões excedentes viáveis depois te der ocorrido os procedimentos de Fertilização in vitro ou Injeção Intracitoplasmática de Espermatozoide.

Essa destinação que se dá aos embriões excedentes, provoca algumas discussões éticas, tendo em vista que alguns embriões não sobrevivem a técnica de congelamento, ferindo assim alguns princípios éticos e morais.

Outro grande problema ao escolher pelo congelamento embrionário é prever quanto tempo esses embriões ficaram congelados, ocasião que podem cair no esquecimento.

Para diversos pesquisadores e doutrinadores, a criopreservação se torna aceita do ponto de vista ético se esse for um meio desses embriões gerarem vidas futuras, e ainda que as possibilidades sejam limitadíssimas, esses embriões são vidas e como tal devem ser considerados.

O CFM10, em sua resolução no 2.168/2017, autorizou para as clinicas de fertilização o descarte dos embriões congelados, que estão guardados por um período maior de 3 anos, mas para isso é necessário o consentimento dos genitores para tal ato.

\section{V- CRIOPRESERVAÇÃO DE GAMETAS OU EMBRIÕES}

1. As clínicas, centros ou serviços podem criopreservar espermatozoides, oócitos embriões e tecidos gonádicos. 2. O número total de embriões gerados em laboratório será comunicado aos pacientes para que decidam quantos embriões serão transferidos a fresco conforme determina esta Resolução. Os excedentes, viáveis, devem ser criopreservados. 3. No momento da criopreservação, os pacientes devem manifestar sua vontade, por escrito, quanto ao destino a ser dado aos embriões criopreservados em caso de divórcio ou dissolução de união estável, doenças graves ou falecimento de um deles ou de ambos, e quando desejam doá-los. 4. Os embriões criopreservados com três anos ou mais poderão ser descartados se esta for a vontade expressa dos pacientes. 5. Os embriões criopreservados e abandonados por três anos ou mais 
podem ser descartados. Parágrafo único: Embrião abandonado é aquele em que os responsáveis descumpriram o contrato pré-estabelecido e não foram localizados pela clínica.

\subsection{Doações de gametas}

Para abordar o tema de doação de gametas, que se entende por doação de sêmen ou de oócitos, é importante salientar que o ordenamento jurídico brasileiro não há leis especificas e esclarecedores das dúvidas que surgem sobre o assunto.

A doação de gametas é utilizada quando é caracterizado a ausência de formação de oócitos por parte da mulher, falta de espermatozoide por parte do homem ou nos casos em que existe risco de transmissão de doenças genéticas.

Quando o casal opta por usar material genético de um terceiro surgem questões do tipo: sigilo sobre a identidade do doador, riscos de consanguinidade, forma como serão obtidos entre outras.

A resolução 2.168/2017 do CFM $^{10}$ deixa especificado o que pode e quais as regras para a doação de gametas e consequentemente também de embriões como verificamos a seguir:

\section{IV - DOAÇÃO DE GAMETAS OU EMBRIÕES}

1. A doação não poderá ter caráter lucrativo ou comercial. 2. Os doadores não devem conhecer a identidade dos receptores e vice-versa. 3. A idade limite para a doação de gametas é de 35 anos para a mulher e de 50 anos para o homem. 4 Será mantido, obrigatoriamente, sigilo sobre a identidade dos doadores de gametas e embriões, bem como dos receptores. Em situações especiais, informações sobre os doadores, por motivação médica, podem ser fornecidas exclusivamente para médicos, resguardando-se a identidade civil do (a) doador (a). 5. As clínicas, centros ou serviços onde são feitas as doações devem manter, de forma permanente, um registro com dados clínicos de caráter geral, características fenotípicas e uma amostra de material celular dos doadores, de acordo com legislação vigente. 6. Na região de localização da unidade, o registro dos nascimentos evitará que um (a) doador (a) tenha produzido mais de duas gestações de crianças de sexos diferentes em uma área de um milhão de habitantes. Um (a) mesmo (a) doador (a) poderá contribuir com quantas gestações forem desejadas, desde que em uma mesma família receptora. 7. A escolha das doadoras de oócitos é de responsabilidade do médico assistente. Dentro do possível, deverá garantir que a doadora tenha a maior semelhança fenotípica com a receptora. 8. Não será permitido aos médicos, funcionários e demais integrantes da equipe multidisciplinar das clínicas, unidades ou serviços participar como doadores nos programas de RA. 9. É permitida a doação voluntária de gametas, bem como a situação identificada como doação compartilhada de oócitos em RA, em que doadora e receptora, participando como portadoras de problemas de reprodução, compartilham tanto do material biológico quanto dos custos financeiros que envolvem o procedimento de RA. A doadora tem preferência sobre o material biológico que será produzido

Primeiramente tem que se observar que a doação de gametas é liberada pelo CFM desde que sigam as normas descritas na resolução citada acima. Pode-se notar, então, que é importantíssimo que a doação não tenha caráter lucrativo e que se guarde o anonimato do doador. Apenas médicos que estão envolvidos com a doação podem estar a par dos dados do doador, mas apenas de seus dados clínicos e nunca de seus dados civeis.

Para ser doador o homem pode ter até 50 anos e a mulher até 35 anos. Um cuidado importantíssimo é que o material genético do doador pode gerar apenas 2 filhos de sexos diferentes em uma área com um milhão de habitantes, e por fim, é vedada a participação da equipe multidisciplinar da clinica em que está sendo realizada a RA como doador de gametas.

\subsubsection{Conflitos jurídicos na doação de ga- metas}

O conflito gerado pela doação é que deve prevalecer o anonimato do doador ou sempre deve prevalecer o direito do ser humano gerado pelas técnicas de RA saber qual sua identidade genética? 
Mesmo sem muito aprofundamento sobre o assunto pode-se ter a noção que todo ser humano tem o direito de saber sua origem biológica e seu patrimônio genético, porem quando a criança advém de uma técnica que utilizou doação de gametas esse direito se vê prejudicado em razão da garantia de anonimato que o doador possui, essa discussão esta integralmente ligada a dignidade da pessoa humana.

No Código Civil Brasileiro no artigo 1.597, $\mathrm{V}$, temos que no "Art. 1.597, presume-se concebidos na constância do casamento os filhos: [...] $\mathrm{V}$ - havidos por inseminação artificial heteróloga, desde que tenha prévia autorização do marido. “. O inciso $V$ desse referido artigo deixa claro que basta que haja consentimento do marido antes da realização da RA, isso nos leva a concluir que - legislador considera a filiação socioafetiva acima da filiação biológica, não cabendo no ordenamento jurídico possibilidade de reclamação de paternidade por parte dos doadores ou requerimento de negativa de paternidade por parte do pai que consentiu para que houvesse a tentativa no tratamento de RA.

Mesmo havendo essa disposição pelo Código Civil, o Brasil não dispõe de uma norma no ordenamento jurídico que regulamente o direito da pessoa, gerada por RA heteróloga, buscar sua verdadeira identidade genética.

A importância de normatização desse assunto seria em razão de envolver direito da personalidade e da dignidade da pessoa humana, mas tem que prevalecer o interesse legítimo de descobrir a origem genética da parte interessada, trazendo proteção contra possíveis doenças genéticas e resguardo à existência.

\subsection{Cessão temporária do útero}

A utilização da técnica de cessão temporário do útero ou "barriga solidaria", é indicada nos casos em que a mulher que deseja engravidar possui algumas barreiras para que isso possa se tornar realidade como exemplo, síndrome de Rokitansky (ausência ou má formação no útero), já passaram por cirurgias para retirada do útero, alterações anatômicas do órgão, algum tipo de contraindicação à gravidez ou em caso de relação homoafetiva.
Para realização da "barriga solidaria" é preciso que uma outra mulher gere o embrião com origem de fecundação heteróloga ou homóloga de um casal. O CFM em sua resolução 2.168/2017 coloca várias regras que que possa ser utilizada essa técnica. Como se pode ver a seguir:

\section{VII-SOBRE A GESTAÇÃO DE SUBSTITUIÇÃO (CESSÃO TEMPORÁRIA DO ÚTERO)}

As clínicas, centros ou serviços de reprodução assistida podem usar técnicas de RA para criarem a situação identificada como gestação de substituição, desde que exista um problema médico que impeça ou contraindique a gestação na doadora genética, em união homoafetiva ou pessoa solteira. 1. A cedente temporária do útero deve pertencer à família de um dos parceiros em parentesco consanguíneo até o quarto grau (primeiro grau-mãe/filha; segundo grauavó/irmã; terceiro grau- tia/sobrinha; quarto grau-prima). Demais casos estão sujeitos à autorização do Conselho Regional de Medicina. 2. A cessão temporária do útero não poderá ter caráter lucrativo ou comercial. 3. Nas clínicas de reprodução assistida, os seguintes documentos e observações deverão constar no prontuário da paciente: 3.1.Termo de consentimento livre e esclarecido assinado pelos pacientes e pela cedente temporária do útero, contemplando aspectos biopsicossociais e riscos envolvidos no ciclo gravídico-puerperal, bem como aspectos legais da filiação; 3.2. Relatório médico com o perfil psicológico, atestando adequação clínica e emocional de todos os envolvidos; 3.3 Termo de Compromisso entre o (s) paciente (s) e a cedente temporária do útero (que receberá o embrião em seu útero), estabelecendo claramente a questão da filiação da criança; 3.4. Compromisso, por parte do (s) paciente (s) contratante (s) de serviços de RA, de tratamento e acompanhamento médico, inclusive por equipes multidisciplinares, se necessário, à mãe que cederá temporariamente o útero, até o puerpério; 3.5 . Compromisso do registro civil da criança pelos pacientes (pai, mãe ou pais genéticos), devendo esta documentação ser providenciada durante a gravidez; 3.6. Aprovação do cônjuge ou companheiro, apresentada por escrito, se a cedente temporária do útero for casada ou viver em união estável. 
Como regra a mulher que vai gerar o embrião, deve pertencer a família de um dos parceiros. Nos casos em que não há essa possibilidade devem ser analisados e ter uma previa autorização do Conselho Regional de Medicina.

Outro aspecto importantíssimo a ser observado é que só se permite o procedimento se for um ato sem fim lucrativo, não podendo assim a mulher que vai engravidar ser remunerada para isso.

Embasando essa premissa, de não ter caráter lucrativo ou comercial, a Constituição Federal não permite qualquer tipo de comercialização que envolva remoção de órgãos, tecidos ou substâncias humanas, independente da finalidade. Como se pode analisar o disposto no artigo 199, $\S 4$ ㅇ da Constituição Federal:

Art. 199. A assistência à saúde é livre à iniciativa privada.

[...]

$\S$ 4으 A lei disporá sobre as condições e os requisitos que facilitem a remoção de órgãos, tecidos e substâncias humanas para fins de transplante, pesquisa e tratamento, bem como a coleta, processamento e transfusão de sangue e seus derivados, sendo vedado todo tipo de comercialização.

A doadora temporária do útero merece atenção e deve passar sempre por uma avaliação psicológica antes de ser feito qualquer tipo de tratamento. É importante levar em conta nessa análise quais foram as motivações para gerar uma criança para um outro casal e qual o real vínculo com os mesmos.

Para a doadora que possui família constituída, é casada e tem filhos, essa avaliação merece ainda mais atenção por gerar na sua própria família e em seu casamento algumas implicações. E outro ponto importante, a doadora precisa também saber lidar com os questionamentos que a sociedade irá fazer e até mesmo com os pré-julgamentos que iram lhe fazer.

É preciso garantir que a mulher que está gestando o bebê estará preparada para entrega-lo aos seus verdadeiros pais assim que nascer e o vínculo com a doadora não prejudicará o relacionamento entre pais e filho.

Contudo essa técnica tem pouco respaldo na legislação brasileira, como se nota, diretamente temos apenas a resolução do CFM tratando do assunto. Por essa razão que para que a técnica não crie problemas sociais tanto para doadora quanto para o bebê gerado é importantíssimo que se apresente, sem demorar, no ordenamento jurídico, soluções para possíveis conflitos tanto no campo ético quanto jurídico.

\subsection{RA post-mortem}

O CFM em sua resolução 2.168/2017 permite a utilização do embrião congelado no caso do falecimento de um dos cônjuges. É permitida a reprodução assistida post-mortem desde que haja autorização prévia específica do(a) falecido(a) para o uso do material biológico criopreservado, de acordo com a legislação vigente.

No mais, adotar esse procedimento ainda gera muita discussão no campo ético e biológico. Uma das grandes preocupações é a analise da estrutura familiar, quais serão os direitos dessa criança, e como se dá em caso de bens deixados pelo cônjuge falecido.

Em razão do direito brasileiro pouco transcorrer sobre o assunto, a doutrina se divide em três correntes. Tem doutrinadores que defendem a total proibição, outros acham aceitável a RA postmortem, mas a criança gerada não terá direito a herança do genitor falecido e por fim tem os que defendem a possibilidade de uso da técnica garantindo ao sucessor os efeitos sucessórios.

Porém o Código Civil Brasileiro de 2002 transcorre em seu artigo 1.597, inciso III, o seguinte:
Art. 1.597. Presumem-se concebidos na constância do casamento os filhos:
I - nascidos cento e oitenta dias, pelo me- nos, depois de estabelecida a convivência conjugal;
11 - nascidos nos trezentos dias subse- quentes à dissolução da sociedade conju- gal, por morte, separação judicial, nulida- de e anulação do casamento;
III - havidos por fecundação artificial ho- móloga, mesmo que falecido o marido.

A previsão legal presume como filho concebidos na constância do casamento os que foram gerados por meio da RA homologa, técnica em que usa o material genético do próprio marido, o Código Civil nada fala da fertilização heteróloga. 
Apresentado como regra para a criopreservação, o casal que tem embriões excedentes deve assinar um termo de consentimento e nele deixar claro o que deseja que seja feito nos casos de fatalidades. Nesse caso, o embrião transplantado será esse embrião excedente que o cônjuge falecido já deixou autorização prévia para sua utilização em caso de sua ausência.

O entendimento majoritário então deixa claro que com a prévia autorização do cônjuge para a utilização desse material genético, pode-se presumir a paternidade do filho concebido por RA post-mortem.

\subsection{RA e casais homoafetivos}

Os casais homoafetivos que desejam ter um filho podem recorrer, além da adoção, às técnicas de RA.

A resolução 2.168/2017 do CFM discorre sobre o tema em alguns pontos como:

\section{II - PACIENTES DAS TÉCNICAS DE RA}

[...]

2. É permitido o uso das técnicas de RA para relacionamentos homoafetivos e pessoas solteiras, respeitado o direito a objeção de consciência por parte do médico. 3. É permitida a gestação compartiIhada em união homoafetiva feminina em que não exista infertilidade. Considera-se gestação compartilhada a situação em que o embrião obtido a partir da fecundação do (s) oócito (s) de uma mulher é transferido para o útero de sua parceira.

Assim, fica permitido pelo Conselho a utilização das técnicas de RA para relacionamentos homoafetivos e permite que seja realizada a gestação compartilhada nos casos de casal composto por duas mulheres, em que não exista infertilidade.

A opção de gestação compartilhada consiste na utilização do oócito de uma das mulheres, que será fecundado por um espermatozoide de um doador desconhecido, e posteriormente será transferido o embrião para o útero da outra muIher, tendo as duas oportunidades de participar da concepção do bebê.

Porém, quando formado por duas mulheres, pode-se ainda apenas fertilizar com o sêmen de um doador desconhecido o oócito de uma delas, e essa mesmo gerar o bebê, sendo assim o oócito e a gestação tudo em uma única mulher.

Para os casais compostos por dois homens a técnica adotada é da cessão temporária de útero, sendo que eles precisam de uma doadora de oócito e uma outra mulher que seja da família para gerar o embrião que nela será implantado. Nessa hipótese o sêmen de um deles é utilizado para fecundar o oócito doado.

\subsection{Consequências jurídicas}

Nesses casos de casais homoafetivos, o que poderia ser um pouco mais complicado seria o registro civil das crianças advindas dessas técnicas apresentadas anteriormente. Porém a Corregedoria Nacional de Justiça ${ }^{12}$ publicou o Provimento no 52, de 14 de março de 2016 que regulariza a emissão de certidão de nascimento dos filhos concebidos por meio de RA e da cessão temporária do útero.

O provimento abrange tanto os casais homoafetivos ou heteroafetivos, não havendo nenhum tipo de distinção. Anterior a essa regulamentação era necessária autorização judicial para que houvesse o registro, porém atualmente os pais que forem casados ou que vivem em união estável, pode apenas um deles comparecer ao cartório e realizar o registro e, além do mais, nos casos de casais homoafetivos, na certidão de nascimento não haverá distinção quanto a ascendência materna ou paterna.

E por fim, na utilização da cessão temporária de útero, não mais constará na Declaração de Nascidos Vivos realizada pelo hospital o nome da mulher que deu à luz ao bebê como mãe do mesmo.

\subsection{RA e planos de saúde}

Quando o casal recebe a noticia que terão que recorrer as técnicas de RA logo procuram auxilio do plano de saúde para custodiar as despesas dos procedimentos.

Isso porque, um tratamento de RA pode custar para a paciente em torno de 7 a 8 salários mínimos vigente no país, não incluindo nesse montante todo o medicamento que precisa ser administrado durante o acompanhamento e procedimento. 
Porém, ao requererem esse auxilio por parte dos planos de saúde recebem a negativa com a justificativa que não há no plano contratado cobertura para esse tipo de tratamento. Porém essa recusa é totalmente inconstitucional tendo em vista que a Constituição Federal garante aos cidadãos o exercício do direito ao planejamento familiar. Direito esse, que está expressamente no art. 226, §7으 da Constituição Federal de 1988:

Art. 226. A família, base da sociedade, tem especial proteção do Estado.

$\S 1$ ㅇ O casamento é civil e gratuito a celebração.

$\S 2$ o O casamento religioso tem efeito civil, nos termos da lei.

§ 3o Para efeito da proteção do Estado, é reconhecida a união estável entre o homem e a mulher como entidade familiar, devendo a lei facilitar sua conversão em casamento.

§ 4을 Entende-se, também, como entidade familiar a comunidade formada por qualquer dos pais e seus descendentes.

$\S 5$ ㅇ Os direitos e deveres referentes à sociedade conjugal são exercidos igualmente pelo homem e pela mulher.

$\S 6$ o O casamento civil pode ser dissolvido pelo divórcio. (Redação dada Pela Emenda Constitucional no 66, de 2010)

$\S 7$ ㅇ Fundado nos princípios da dignidade da pessoa humana e da paternidade responsável, o planejamento familiar é livre decisão do casal, competindo ao Estado propiciar recursos educacionais e científicos para o exercício desse direito, vedada qualquer forma coercitiva por parte de instituições oficiais ou privadas.

§ 8ㅇ O Estado assegurará a assistência à família na pessoa de cada um dos que a integram, criando mecanismos para coibir a violência no âmbito de suas relações.

Com essa resolução da Constituição Federal, faz com que os planos de saúde em todos os seus contratos tragam a previsão de dar ao contratante o direito a RA. Porém para fixar essa ideia constitucional, a lei no 9.263/96 regulamenta esse entendimento no art. 9o: "Para o exercício do direito ao planejamento familiar, serão oferecidos todos os métodos e técnicas de concepção e contracepção cientificamente aceitos e que não coloquem em risco a vida e a saúde das pessoas, garantida a liberdade de opção".

Caso em que ocorra a negativa por parte dos planos de saúde a parte prejudicada pode entrar com ação contra essa prática abusiva. Como se pode observar na apelação do processo no 0012087-34.2012.8.26.0562, julgada pela 10으 Câmara de Direito Privado' ${ }^{13}$ em 03.02.2015:

PLANO DE SAÚDE - Exclusão contratual da fertilização in vitro - Abusividade - Violação à Lei no.9.656/98, que expressamente estabelece a obrigatoriedade de cobertura do atendimento nos casos de planejamento familiar - Patologia, ademais, prevista na Classificação Estatística Internacional de Doenças e Problemas Relacionados com a Saúde, da Organização Mundial de Saúde - Ação procedente - Sentença reformada - RECURSO PROVIDO.

Contudo, pode-se notar que o direito de acesso as técnicas de RA está garantido, por meio das legislações apresentadas e jurisprudências, sendo indiscutível a cobertura contratual para as técnicas de RA, como prescrito pelo médico.

\section{CONCLUSÕES}

A bioética e o biodireito são dois campos do saber que procuram verificar as interações entre os seres humanos e suas condutas na utilização de biotecnologias e da própria ciência. Estas duas áreas do conhecimento humano têm como foco a análise sobre o que é eticamente correto e como pode-se aplicar as tecnologias no campo da ciência em nosso cotidiano.

O biodireito é norteado pelo surgimento muito rápido de novas técnicas, como por exemplo de RA, e com isso percebeu-se a falta de normas a serem seguidos por profissionais e pacientes, causando uma grande insegurança jurídica. Assim o biodireito surge com a ideia de estabelecer relação e normatização entre bioética e o direito, observando sempre os princípios de respeito a vida. 
Ainda sobre o tema, nota-se que a RA está ligada diretamente ao biodireito, pois trazem intervenções medicas como técnicas, que para serem eticamente corretas precisam observar algumas regras de conduta e segurança.

Quando um casal opta por realizar um procedimento de RA muitas dúvidas surgem, porém várias não são normatizadas pelo direito trazendo inseguranças como já citado. Essas inseguranças trazem consequências as vezes graves até mesmo nas condutas da equipe multidisciplinar, que mesmo achando que está agindo conforme a legislação brasileira, a conduta na verdade pode ser antiética e até mesmo criminosa.

Verificamos por meio dos vários tópicos apresentados neste trabalho, que a legislação brasileira é falha quanto ao assunto relacionado a RA, causando grande desconforto aos seus usuários. Principalmente ao se tratar dos prontos polêmicos como: embriões excedentes, congelamento de embriões, doação de gametas, cessão temporária do útero, RA post-mortem, os casos em que envolvem casais homoafetivos e a RA sobre a lente dos planos de saúde.

Nos casos de haver embriões excedentes e posteriormente o seu congelamento causa polêmica pelo fato da destinação desses embriões depois de um certo tempo não ser exata e nem fiscalizada, causando alguns desconfortos e insegurança tanto para o paciente como para a equipe médica.

Ao discutir sobre a RA post-mortem, o problema é amplo e pouco explorado pela legislação, pois ao ter embriões congelados que poderão ser usados depois da morte do pai, causa também insegurança, por não ser definido limites para essa utilização, do ponto de vista sucessório.

Outra polêmica, cada vez mais discutida é a respeito das frequentes negativas pelos planos de saúde, que consideram que por não haver previsão contratual não são obrigados a cobrir todos os custos com o tratamento para RA, essa questão está sendo discutida e há diversas jurisprudências sobre essa problemática, no qual se pode concluir que em um futuro próximo espera-se haver menos negativas pelos planos de saúde.
Assim, uma das soluções seria o projeto de lei que tramita no congresso, para que possa ter uma luz, com soluções para afastar essa insegurança que os profissionais e os pacientes sentem ao se discutir o assunto.

\section{REFERÊNCIAS}

1-Pessini L, Barchifontaine CP. Problemas atuais de bioética. 10ạ ed. São Paulo. Centro Universitário São Camilo. 2012.

2- Scalquette ACS. Estatuto da reprodução assistida. São Paulo. Saraiva, 2010.

3- Nogueira Filho LN. Estatuto ético do embrião humano. Revista Bioethikos - Centro Universitário São Camilo - 2009;3:225-34. Disponível em: http:// www.saocamilo-sp.br/pdf/bioethikos/71/225234.pdf [Acesso em: 07.07.2016]

4- BRASIL. Constituição (1988). Constituição da República Federativa do Brasil. Brasília, DF: Senado Federal: Centro Gráfico, 1988. 292 p.

5- BOBBIO N. A Era dos Direitos. 13a ed. - Rio de Janeiro. Elsevier. 2004

6- ONU. Declaração Universal dos Direitos Humanos. 1948. Disponível em: http://unesdoc.unesco.org/ images/0013/001394/139423por.pdf [Acesso em: 24.10.2016]

7- UNESCO. Declaração Universal sobre Bioética e Direitos Humanos. 2006. Disponível em: http:// unesdoc.unesco.org/images/0014/001461/ 146180por.pdf [Acesso em: 24.10.2016]

8- Zegers-Hochschild F, Schwarze JE, Crosby J, Musri C, Urbina MT. Assisted reproduction techniques in Latin America: the Latin American Registry, 2014. Latin American Network of Assisted Reproduction (REDLARA). Reprod Biomed Online. 2017;35:28795.

9- Diniz MH. O estado atual do biodirieto. 9a ed. São Paulo. Saraiva. 2014.

10- BRASIL. Resolução 2.168/2017 do Conselho Federal de Medicina, publicada no D.O.U. de 21 setembro de 2017.

11- BRASIL. Projeto de Lei 115/2015, de 3 de fevereiro de 2015. Disponível em: http://www.camara.gov.br/ sileg/integras/1300959.pdf [Acesso em: 15.08.2016].

12- BRASIL. Provimento $\mathrm{n} 052$ da Corregedoria Nacional de Justiça, de 14 de março de 2016. Disponível em: http://www.cnj.jus.br/files/conteudo/arquivo/2016/ 03/6bd953c10912313a24633f1a1e6535e1.pdf. Acesso em: 15.08.2016

13- BRASIL. Tribunal de Justiça do Estado de São Paulo. Apelação. Plano de Saúde. Apelação no 001208734.2012.8.26.0562 10 a Câmara de Direitos Privado Relator: Elcio Trujillo. São Paulo, SP, 3 fevereiros 2015. Disponível em: http://tj-sp.jusbrasil.com.br/ jurisprudencia/ 165471911 / apelacao-apl120873420128260562 -sp-00120873420128260562/inteiro-teor-165471919 Acesso em: 21.10.2017. 